\title{
The Moral Desirability of Presentism
}

\author{
by \\ Francesco Orilia \\ Università di Macerata \\ Dipartimento di Studi Umanistici - Lingue, Mediazione, Storia, Lettere, Filosofia \\ Sezione di Filosofia e Scienze Umane \\ via Garibaldi, 20 \\ 62100 Macerata \\ ITALY \\ orilia@,unimc.it
}

\begin{abstract}
In a presentist world there are no past events and thus a fortiori no past painful events. Presentists have thus argued that relief is appropriate only from their point of view and have appealed to this claim to back up their ontology. There are well-known anti-presentists strategies to counter this move. Nevertheless, one can still argue that the rejection of past painful events that comes with presentism makes this doctrine morally superior to non-presentists world views. If so, at least for those who think that the presentist vs. non-presentist dispute cannot be decided on purely theoretic grounds, or for those who endorse a theistic perspective, or at least believe in the ontological efficacy of values, there is a reason in favor of the truth of presentism.
\end{abstract}

\section{Introduction}

In the current debate on time we find a dispute between presentists, according to whom only what is present exist, and non-presentists, who deny that the present exhausts reality; these two groups advertise, we may say, a presentist world and a non-presentist world, respectively. Here I shall put forward a line of reasoning to the effect that a presentist world is morally more valuable than a nonpresentist world, ${ }^{1}$ and then I shall also speculate on whether this gives us some reason to consider presentism true and non-presentism false, so as to move, as we may put it, from the claim that presentism ought to be true to the claim that it is true.

I have argued elsewhere (Orilia 2016) in favor of a certain version of presentism, moderate presentism, which restricts the claim that whatever exists is present to events and allows for past and

\footnotetext{
${ }^{1}$ I have already quickly voiced this thesis in previous works (Orilia 2012, 2014). In this paper, I try to defend it in detail.
} 
future times (understood in a substantialist sense) and for past objects (understood, following Williamson 2002, as "ex-concrete"). My argument will turn around the existence or non-existence of past events and has nothing to do with whether or not there are past (ex-concrete) objects and past times. Hence, strictly speaking, my argument (if successful) supports primarily the desirability of moderate presentism, rather than the standard version of presentism, which we may call typical presentism. Similarly, the leap from ought to is that I have evoked in the previous paragraph regards primarily moderate presentism rather than typical presentism. Nevertheless, for simplicity's sake, the distinction between these two version of presentism can be set aside and I shall thus speak of presentism tout court (my proposal can be taken to support presentism in general, even though it supports more directly the moderate rather than the typical version of this doctrine).

The just considered disagreement in the presentist camp is really minor compared to what one finds in turning to non-presentism, for this comes, as is well-known, in various wildly conflicting forms (see, e.g., Markosian 2010). It includes philosophers who are A-theorists like the presentists, in that they share the belief in an objective present, but are either eternalists or pastists (as both growing blockers and branching futurists may be called). The former acknowledge in addition to the present both an objective past and an objective future, whereas the latter simply add an objective past. Moreover, most conspicuously, non-presentism includes eternalists of the B-theoretical variety, who acknowledge past, present and future only in a subjective sense, parasitic on objective relations of temporal precedence and simultaneity. For present purposes, however, these divergences in the non-presentist camp are of limited importance and will be ditched as far as possible.

My contention in this paper is inspired by the famous thank goodness argument for presentism by Prior $(1959,1996)$ and it is thus appropriate and perhaps also useful to proceed by first recalling its main point, or at least the one that is relevant here, as well as some well-known anti-presentist reactions to it.

\section{Prior's argument and some clarifications}

Let us suppose once more, with Prior, that after a severe headache, a demanding exam or a painful visit to the dentist, somebody exclaims with relief: "Thank goodness that's over." From a presentist perspective the unpleasant event no longer exists, whereas it is somehow in the ontological inventory from a non-presentist standpoint. Presentists have thus argued that the relief is appropriate or justified only from their point of view and have appealed to this to back up their ontology. In particular, Prior $(1959,1996)$ has argued in this way specifically against B-eternalists, whereas 
Zimmerman (2008, pp. 214-216, p. 224, n. 5) has raised this issue also against pastists and A-eternalists ${ }^{2}$ (beside pointing out that presentists can also justify disappointment for the cessation of pleasure in a way that is not open to eternalists and pastists).

It seems clear that this line can hardly convince non-presentists, for there are ways to see the relief as justified even from an eternalist or a pastist standpoint. The A-eternalist can insist on the objective pastness of the unpleasant experience (Schlesinger 1980) and similarly can the pastist, whereas the B-eternalist can point out that the experience objectively precedes the belief that one is no longer undergoing it, whether this belief is taken to be tensed (MacBeath 1983, Mellor 1998, Oaklander 2003) or tenseless and token-reflexive (Smart 2008). ${ }^{3}$ Moreover, the non-presentist response can be embellished with further sophisticated considerations based on evolutionary theory (MacLaurin and Dyke 2002) or even statistical mechanics and cosmic thermodynamics (Smart 2008, p. 234).4

Before going ahead, it is important to clarify how we should understand tenses or words such as "past" in a cross-theoretical dispute of this sort, in which they may be taken in different ways by different parties. First of all, we should grant that the B-eternalist who does not acknowledge primitive tenses can feel free to read the past tense in her own favorite way. From their perspective, for example, the assertion that Arthur was undergoing his most demanding exam, or that the event of Arthur's undergoing his most demanding exam is past, can be understood as the assertion that the event of Arthur's undergoing his most demanding exam precedes my tokening these words (or along similar lines). Moreover, we should admit, from a non-presentist perspective, that the present tense can be read in a tenseless way; for instance, from this perspective, the claim that the event of Arthur's undergoing his most demanding exam is past (or precedes this utterance) can be taken to imply that the event in question is part of reality, that it somehow belongs to the ontological inventory, without however implying that it occurs now (simultaneously with my tokening these words), or, so to speak within the present slice of reality (the one containing all the events simultaneous with my tokening these words). I shall take all of this for granted in developing and defending my argument in the following.

\section{The argument for the moral desirability of presentism}

\footnotetext{
${ }^{2}$ Although Prior was certainly an A-theorist, some doubts can be raised on whether he was (always) a presentist (see n. 5 in Hoerl 2015 and references therein). For the purposes of this paper we need not worry about this interpretative matter. For clarity's sake, it is also worth noting that I neglect here a well-known semantic aspect of the argument, which has to do with whether a B-theorist has the resources to correctly interpret "thank goodness that's over" and related expressions. This aspect is perhaps predominant in Prior and in most commentators, but I set it aside, since it is not directly relevant for my concerns in this paper.

${ }^{3}$ The first option gives rise to the so-called new B-theory, whose supporters face the problem of preventing the leap from the existence of tensed propositional attitudes to the existence of tensed facts (see Chen 2011 for a general discussion). The second option avoids this complication and may thus be better for the B-theorist, if the problems typically associated to the other alternative can be overcome (Orilia and Oaklander 2015).

${ }^{4}$ For further anti-presentist rejoinders, see Turri 2013 and Hoerl 2015.
} 
The anti-presentist reactions to Prior's argument may well convince us that relief makes sense even in a non-presentist world. Yet, they leave a crucial point intact, namely that in such a world all past events exist, are somehow part of reality, so that, a fortiori, all past painful events are part of reality; whereas, in a presentist world, no past events are part of reality and hence, a fortiori, no past painful events are part of reality.

These considerations, at least prima facie, suggest that a presentist world is morally more desirable than a non-presentist world, wherefrom it follows that it is morally desirable that presentism be true and non-presentism false. This is so in the light of a very basic axiological principle, which I believe most us are inclined to take for granted: pain is in itself a negative value, something objectively undesirable in a broadly moral sense; in a nutshell: its absence is morally more valuable than its presence.

Before seeing in more detail how this principle supports presentism, it may be worth considering a couple of objections to it that may come to mind. ${ }^{5}$ Somebody might complain that the desirability in question is not really "moral," since pain would be negative even in a world without moral agents, e.g. a world with only lower-level animals, which, though incapable of moral behavior, are nevertheless capable of suffering. It should be conceded however that the negativity of pain grounds a most fundamental moral constraint, namely that one should never inflict unnecessary pain. And thus I think that it is appropriate to qualify as moral the undesirability of pain and the desirability of its absence, despite the possibility of a world with pain and without moral agents. At any rate, for those who insist in considering my use of "moral" out of place, the argument on offer here should still retain some force as an argument for the desirability, tout court, of presentism. Next, it could be pointed out that pain can be necessary to attain a positive result, as when we undergo surgery to cure a disease; or that it can be a crucial ingredient of hardships, trials and ordeals whose endurance stimulates new skills and capacities that enhance progress and well-being at both the individual and the social level. Sure enough; the point, however, is that, even if we recognize an instrumentally positive role for pain in the achievement of such results, it is not the pain, qua pain, that is valuable and desirable, but the results themselves.

Let us then assume that the axiological principle in question is acceptable. Its purchase is not however sufficient to argue for the higher desirability of a presentist world; we need to appeal to the empirical fact that there was pain and sorrow, and actually, in doing so, it seems appropriate to bring to the fore not so much relatively minor past offences, such as the headache or the demanding exam

\footnotetext{
5 Thanks to Tomis Kapitan for having urged them.
} 
considered by Prior, but pain and sorrow of a quite superior magnitude. ${ }^{6}$ Unfortunately, it is all too easy to find gigantic samples of evil that furnish what is needed here. Think for instance of the Holocaust.

If the Holocaust is real as the non-presentist has it, no matter how much we struggle to make the world a better world, all the intolerable pain, grief and injustice that came with it are still concretely experienced in their unbearable fullness somewhere in spacetime. If we seriously concentrate on that, the thought that all that suffering is part of reality should come as a great moral burden, deserving the same empathic sorrow reserved for the suffering around us in our current temporal location. This burden should stand, no matter how relieved we can feel in thinking that the suffering in question lies in a part of reality that precedes ours, and that we can causally contribute to make the stretch of reality ahead of us more comfortable than the one that lies behind. Indeed, the burden may well be compounded by the thought that, precisely because of this lying behind, we can do nothing even in principle to extinguish or at least alleviate the suffering. In contrast, in a presentist world the Holocaust is no part of reality, and thus the empathic sorrow appropriate in a non-presentist world is not called for. There are of course Holocaust memories and documents that upset us and hopefully play a causal role in preventing future evil. And we can and should feel sorry that the Holocaust happened and even be terrified by this thought. But thinking that the Holocaust is part of reality, as in a non-presentist world, is a much deeper burden.

In summary, the pro-presentist argument, as we may call it, is this:

(P1) Absence of pain is morally more valuable than presence of pain.

(P2) If there were past painful events, then: (i) they are part of reality, if the world is non-presentist; (ii) they are not, if the world is presentist. ${ }^{7}$

(P3) There were painful events, actually extremely dreadful ones, such as those involved the Holocaust.

Hence,

(C) a presentist world is morally more valuable than a non-presentist world.

\footnotetext{
${ }^{6}$ Ernesto Graziani recommended that this aspect be emphasized.

${ }^{7}$ For clarity's scrupulous sake, let us emphasize this crucial point: it is not being asserted here that, for non-presentists, past painful events are still part of reality, for of course they do not claim that such events occur now; what is being asserted is that there are, tenselessly speaking, such events.
} 
In order to resist this conclusion, one can of course challenge the reasons invoked in its favor. In philosophy it is hard to take anything for granted and the controversial area we are investigating is no exception. Thus, if not the empirical fact (P3), (P1) and (P2) can perhaps be contested with some subtle reasoning. Yet, it should be conceded that these two premises are solid or at least that, rather than attacking them, it is much more interesting to see whether, with the help of (P3), they can really license $(\mathrm{C})$. I see three objections that stand in the way of this result, at least one of which is pretty much obvious and immediate. Let us thus start with it and then move on to consider the other ones.

\section{The specular argument objection}

We saw that, to reach (C) from (P1) and (P2), (P3) was appealed to. Now, (P3) focuses on the existence of past sorrow. The obvious rejoinder then is an invitation to look at the other side of the coin, namely the existence of past joy, so as to construct a specular anti-presentist argument with the opposite conclusion. Here it is.

(P1') Absence of joy is morally less valuable than presence of joy.

(P2') If there were past joyful events, then: (i) they are not part of reality, if the world is presentist; (ii) they are, if the world is non-presentist.

(P3') There were joyful events, e.g., your favorite exciting ones, or even simply the happily routine episodes of ordinary lives conducted in favorable circumstances.

(C’) A non-presentist world is morally more valuable than a presentist world.

Is there a way to choose between the anti- and the pro-presentist arguments? Or should we rather simply admit that they are on a par and thus consider foolish these attempts to establish the moral superiority of one doctrine over the other? If it were possible to calculate the amounts of past (and future) joy and sorrow and discover that sorrow prevails over joy or vice versa, one could perhaps argue that, depending on the outcome, the former or the latter argument should be preferred. But, as far as I can see, no such calculation is in view and thus one may suspect that we have a stalemate.

However, it seems to me that, independently of any such calculation, the pro-presentist argument sticks out. For the permanence of suffering that comes with non-presentism seems so intrinsically horrifying that it cannot be compensated by any permanence of joy. To put it otherwise, 
whatever comfort we may gain from the thought that pleasant past events survive sub specie aeternitatis, this can hardly balance the dismay for analogous survival of the unpleasant ones: the dismay prevails, even if in the past there had been overall, let us imagine, more good than evil.

Perhaps this analogy will help us see this. Suppose a powerful demon is about to flip a coin with this in mind: if the outcome is cross, it will bring about that a number of people will enjoy an extraordinarily pleasant experience, but at the same time someone will suffer excruciating pain; if the outcome is head, he will do nothing. Perhaps from a perspective such as hedonistic utilitarianism, one could argue that, if the level of pleasure brought about by the pleasant experiences is sufficiently high, the world is better off with them, despite the simultaneous existence of the pain. But this is a very questionable perspective. It seems to me that most of us would not want an unfortunate fellow in excruciating pain, no matter how high the pleasure of the lucky ones, and thus I imagine you will presumably hope that the outcome is head. Similarly, I think, we should prefer a world in which all past painful events are no part of reality, even if this means that all past pleasant events are similarly erased.

For additional support, we can perhaps also adapt to our case Rawls's (1971) device of imagining an original position wherefrom rational agents are supposed to select principles of social arrangements. Since they are under a veil of ignorance that prevents them from knowing which role in society will befall them, all agents, argues Rawls, would choose an arrangement that grants basic liberties to everybody. This rules out, e.g., a society with a minority of slaves ensuring various benefits to members of the majority, for, no matter how high these benefits would be, nobody would want to run the risk of finding oneself in that minority. Similarly, we can imagine an original position wherefrom we can decide whether or not joyful, but also dreadful, events are preserved in the way nonpresentism suggests. Given a veil of ignorance, presumably the non-presentist option would be rejected, since, for all one knows, one could be involved in episodes of excruciating pain or deep sorrow, perhaps in most sections of one's life. The thought that these episodes be parts of reality sub specie aeternitatis is too horrifying to license a preference for non-presentism, even though this also grants the preservation sub specie aeternitatis of joyful events, or so it seems to me.

May be this further consideration can provide another way to support (C) and thus the propresentist argument. In a presentist world, we can conceive that the world as a whole will become pure, that is, with no suffering and no evil, yet still with well-being enjoyed by sentient beings. In contrast, this ideal is banned in a non-presentist world, wherein we can at best hope for the purity from some point onward of the temporal slices of reality lying ahead of us. These slices, pure as they may be, however coexist with impure slices full of suffering and evil, such as those containing the Holocaust events. Hence, even from the perspective of this extremely optimistic outlook, a non-presentist world must perforce be, as a whole, an impure world. 
But again there is the other side of the coin. Nice as the thought of a pure world could be, one can urge, however, that there are other, less cheerful, but perhaps more realistic, possibilities. One of the options considered by modern cosmology is a "Big Crunch" with which the universe, and all life and sentience with it, comes to an end. This scenario may well be depressing and the non-presentist may point out that her world-view has the advantage of making it more bearable: perhaps there is some comfort in thinking that, even if there is a last slice of the universe, all the preceding slices are part of reality, with life and sentience embedded in some of them. True, not only pleasure and joy, but also pain and sorrow, will be found in these slices. Yet, sad as this may be, one could say, there is certainly more value in this way than in the way brought about in a presentist world, for the Big Crunch scenario in such a world would leave us with nothing at all. ${ }^{8}$

What can the presentist reply? in the first place it should be noted that, in the light of the powerful demon and initial position thought experiments, it is not so obvious that in the Big Crunch scenario non-presentism is more desirable than presentism. But even if it were so, all that this proves is that claim (C) must be slightly weakened, by making it conditional on the falsehood of the Big Crunch hypothesis. We shall go back to this in $\$ 7$.

\section{The ugly truthmakers objection}

Notoriously, presentism has to face a truthmaker problem. It arises once we accept the plausible truthmaker principle, according to which (at least some) truths require truhmakers. By its light, true pasttensed propositions, such as the proposition that Caesar crossed the Rubicon, constitute for presentism a difficulty that pastism and eternalism steer clear of. For pastists and eternalists can straightforwardly appeal to past events as truthmakers for them, whereas this move is not open to the presentist. The latter has therefore the burden of extracting from her ontological inventory alternative items that can go proxy for past events in fulfilling this task. (Pastists are in the same boat as presentists when we proceed to consider true future-tensed propositions, such as, let us assume, the proposition that there will be a human expedition to Mars. However, we can ignore this issue here.) One may circumvent this obligation by rejecting the truthmaker principle (Merricks 2007) or denying that past-tensed propositions are ever really true. But the majority of presentists recognize the obligation (rightly so, in my view) and have presented a rich variety of options in order to meet it. For example, Bigelow's Lucretianism (1996) appeals to "propositional" properties (e.g., being such that Caesar crossed the

\footnotetext{
${ }^{8}$ This worry was raised by an anonymous referee.
} 
Rubicon), which the world as a whole exemplifies. ${ }^{9}$ Keller's heacceitism (2004) appeals to present haecceities of past objects and times; Bourne's (2006) and Crisp's (2007) Ersatzism appeal to a precedence relation linking Ersatz times; my own moderate presentism (Orilia 2016) appeals to the exemplification (possibly by ex-concrete objects) of past-tensed properties of the type having been $F$ at $t$, where $F$ is a property and $t$ a past time.

Now, and here comes the objection, ${ }^{10}$ if items of this sort are admitted, there will also be those that make true, now, past-tensed propositions such as the proposition that there was the Holocaust and more specific Holocaust propositions such as that Ann Frank was murdered. And such "ugly" truthmakers make the world a morally ugly world just as evil past events render ugly the non-presentist world. Suppose for example that Lucretianism is right and accordingly the world has now the property of being such that Ann Frank was murdered. Is such a world any better than a non-presentist world in which the event of the assassination of Ann Frank precedes present events such as my writing these words? According to the objection that we are considering the answer is negative, for after all, if Lucretianism is right, the ugliness of the world is testified by its exemplifying the propositional property of being such that Ann Frank was murdered no less than by its including, if presentism is wrong, the event of the assassination of Ann Frank. And such a propositional property will never cease to be exemplified, even in a hypothetical ideal future scenario in which there will be no evil, thereby testifying, even then, the ugliness of our world. No improvement, the objection continues, is offered by the other solutions that the presentist can offer in responding to the truhmaker problem. If haecceitism is true, Ann Frank's haecceity is and always will be appropriately related to the property of being murdered and to the haecceity of the time of the murder in question, in a way sufficient to make it true that Ann Frank was murdered. And this and other truthmakers of this sort are enough to certify the ugliness of our world even in the ideal scenario. Independently of what the presentist will choose, the objection concludes, analogous considerations will be in play.

Convincing as this line might seem at first glance, it overlooks a crucial point. No matter how close the presentists' truthmakers are to the non-presentists' past events, only the latter involve, so to speak, the "real action." And it is only with the real action that there is, in the unfortunate cases, real suffering. Metaphorically speaking, the truthmakers of true past-tensed propositions, whatever they are, can be compared to films shot when certain events were taking place. When the events are gone, the films remain. If the events were unpleasant, they involved suffering, but no suffering is involved in the corresponding films. If a torturing event is filmed, the film can certainly testify that the victim was in pain, but it can do nothing to keep the victim's pain in existence. Those who watch the film may have

\footnotetext{
${ }_{9}^{9}$ Bigelow draws on Lucretius, who however, as noted by Bigelow himself, takes properties of this sort to be exemplified by sections of matter or portions of space.

${ }^{10}$ I owe it to Gregory Landini.
} 
an empathic emotional response to it, but this is another matter. This response is not the victim's pain. If presentism is right, fortunately this pain is no longer around. In contrast, if non-presentism wins the day, the pain is with us in the ontological inventory. True, if presentism wins, we still have the film and cannot get rid of it, whereas, given non-presentism, there is no such film, or at least no need to suppose that there is. But certainly it is better to have the film of the torture than the real torture, for only the latter involves the victim's pain. In sum, this objection does not really undermine (C).

\section{The radical objection}

This last criticism is analogous to the previous one, but it adds a more radical twist to it. ${ }^{11}$ The pro-presentist argument, or for that matter the specular anti-presentist argument as well, relies on a hidden assumption, namely that the moral value of a world is based fundamentally on what is real or existent in that world. But perhaps this assumption could be questioned. Perhaps the value of a world depends equally on what exists and on what existed, i.e. on its history, regardless of whether it is understood in a presentist or non-presentist fashion, to the point that there is no difference in terms of value between a presentist world in which the Holocaust existed and no longer exists and a nonpresentist world in which the Holocaust is part of reality: both are equally bad insofar as they have the same less than impeccable history, and thus we should have no desire to be in one rather than the other. To put it otherwise: any plausible version of presentism has to be combined with a dynamic view of reality. According to presentism, reality is exhausted by what is present, but, additionally, reality changes. So it is not just that reality contains a truthmaker for the past-tense claim that the Holocaust occurred; that there is this truth means that, sometime in the past, before certain changes brought us to the present time, reality was partly constituted by the Holocaust's occurring. So, given this, it seems no better for the Holocaust's merely to have occurred (as the presentist claims) than for the Holocaust to be part of reality (as the non-presentist claims). A further, more emotionally loaded, formulation of this kind of concern has been voiced to me by a presentist friend, Tomis Kapitan, as follows: "I tend to be a presentist, but take utterly no comfort in it. I don't think that a presentist world is 'better' in any sense. Even if I agree that past sufferings are no longer real, they were real, and that's bad enough to cause me considerable anguish. I don't think that reality would be any worse off if eternalism were true. Similarly, past enjoyments are no longer in existence, and sometimes I get delight in reflecting upon them, but I don't think that the world would be any better if reality is a four-dimensional universe."

This objection is radical, because it undermines at its very foundations the inquiry being pursued here. I do not think, however, that it has a real bite. To be sure, there is a grain of truth in it,

\footnotetext{
11 The previously mentioned anonymous referee first raised this issue to me by elaborating on the truthmaker objection.
} 
but once this element is disentangled from the rest, it should be evident that the objection does not stand. One can and should concede that what happened in the past is relevant for the moral evaluation of a world. Thus, for example, a world in which the Holocaust existed is morally far less desirable than a world in which there was no Holocaust. Yet, in a presentist perspective, the fact that certain events were true cannot have the same relevance in the evaluation as the fact that certain other events are true; the latter have a primacy that the former cannot have. For example, it is bad now and forever that an innocent victim was tortured in a concentration camp and thinking of this can elicit now our dismay. Yet, the reality of someone's being tortured, with the excruciating pain of the victim going on now, is worse. In contrast, in a non-presentist perspective, this can hardly be claimed. To see this, it is useful to focus on the analogy between time and space that is often brought up in clarifying what B-type eternalism amounts to. In the latter perspective, the difference between past, present and future is compared to the subjective distinction between far and near: we are distant in a temporal sense from a torture going on in Auschwitz just as we are far in a spatial sense from, say, a planet in Andromeda; and just as the Andromeda planet is as real as the Moon near us, similarly the past torture in Auschwitz is as real as a present torture going on now. But, if this is so, the past torture is as bad as the present one, just as a torture is bad whether it takes place on the far away Andromeda planet or on the nearby Moon. ${ }^{12}$

The picture changes a bit in pastism and A-eternalism. For, according to these doctrines, an objective pastness accrues to past events, and this makes them not fully comparable to spatially distant objects. Yet, it does not really matter for our purposes, unless this pastness makes events somehow less real, to the point that past painful events do not involve suffering and past joyful events do not involve pleasure. If so, however, these doctrines become rather uncomfortable, for they almost seem to embrace contradictiones ex vi terminorum. Here is how Zimmerman (2008, p. 215) makes this point:

... if past headaches are to be much better than present ones, these A-theorists [A-eternalists and pastists] must say things like: a headache is only truly painful when it is present; yesterday's headache, although it exists, is no longer painful ... and that's why it no longer concerns us. ... Although this view makes sense of our relief when pain is past ... it has less appealing consequences as well. Headaches can exist but not be truly painful.

\footnotetext{
12 This is not to say of course that the B-theorist regards spatial distance as the same as temporal distance; the point is simply that for the B-theorist earlier events are real just like spatially distant events. And this point remains no matter how much the B-theorist emphasizes the difference between spatial and temporal relations, e.g. in the way put forward by Oaklander (2015) in his recent defense of a Russellian version of the B-theory called "R-theory," according to which temporal precedence is a primitive unanalyzable external relation.
} 
I have assumed throughout that pastists and A-eternalists do not want to be committed to these past pains that do not hurt. With this assumption they are for present purposes in the same boat as the Beternalists. From the point of view of all of them, past pain should have the same negative moral weight as present pain. In contrast, in the presentist perspective, one can say that a world in which there was pain is worse than a world in which there was no pain, while admitting that present pain is altogether another matter. Of course, if the pastists and the A-eternalists admit past pains that do not hurt, they ipso facto leave, as far as we are concerned here, the B-eternalist's boat and begin to approach the presentist's boat. But they will have to face the concerns raised above.

Despite the above rejoinder, however, it has been suggested to me ${ }^{13}$ that an appropriate mental experiment could provide new fuel for the radical objection. Here is how. So far we have compared, so to speak, our presentist world and our non-presentist world, that is, two worlds both of which have our actual history, a history that unfortunately includes the Holocaust and many other evils. But we may also compare our non-presentist world to a presentist counterfactual world whose history differs from our actual history only because it includes some additional suffering, due, say, to a longer duration of World War II, sufficient for the Nazi to bring to completion their genocidal programs. What is morally preferable, our non-presentist world or the presentist counterfactual world? The supporter of the radical objection may want to suggest here that the former is better, despite the enormous amount of evil that is erased from reality in the latter alternative. Suppose this answer were correct. This seems to back up the intuition that triggers the radical objection. The additional past evil brought about by a longer World War II, devastating as it might have been, is very small, when compared to all the past evil that is part of reality in our non-presentist world. If, in spite of this, our non-presentist world is better than the counterfactual presentist world, this may be taken to suggest that the moral value of a world depends so much on its history that metaphysical considerations regarding the presentist or nonpresentist nature of this history can do little to change the picture.

However, I do not think that this conclusion follows, even if we concede the moral superiority of our non-presentist world over the counterfactual presentist world under consideration. Perhaps, the history of a world matters to a very large extent, an extent larger than we might have thought before this thought experiment; and it is certainly worth investigating why this is so, or at least why it seems to us that it is so. In this investigation, we might find out that the minimal axiological principle (P1) is insufficient to back up this role that we assign to history in judging about the moral value of a world. Nevertheless, this does not yet prove that the way in which metaphysically this history should be considered is irrelevant. It remains true that in a non-presentist world a past pain is as real as a present pain in Andromeda and thus (P1), weak as it may be for other purposes, is strong enough to back up

13 Thanks to Ernesto Graziani for pressing this point. 
the claim that our presentist world is better than our non-presentist world. Perhaps the latter fares better with respect to other presentist worlds, but after all we are interested in our presentist world.

\section{Can we leap from ought to is?}

Suppose that all of this is by and large correct and that we endorse (C). In the light of it we should accept that it is morally desirable that presentism be true. I trust that this result can be considered worthy of note in its own right, but of course its interest increases if it gives us some reason to believe that presentism is true. Does it? Here are my tentative considerations.

The most obvious and immediate reaction to this question, I surmise, is that wishful thinking can hardly settle issues in ontology and that accordingly considerations of the sort I have advanced here are far from proving that presentism is true and non-presentism false. If one comes to accept (C), and yet thinks that from a purely theoretical, ontological, point of view there are compelling arguments against presentism (as many non-presentists hold), the endorsement of (C) may bring some embarrassment, but in itself should not be expected to lead to a conversion to presentism. Consider for example someone who believes that Einstein's relativity theory should be endorsed as part of our best science and that it implies that presentism is false. Such a person presumably will not endorse presentism in the light of $(\mathrm{C})$, even though she might concede that the falsehood of presentism is regretful. However, the matter might be different for those who see the presentism vs. non-presentism dispute as tangled in a theoretical stalemate at the end of the usual round of philosophical arguments in favor or against the options at stake (see, e.g., Sider et al. 2008, chap. 5). Perhaps the pro-presentist argument could incline at least them toward presentism. Given (C), they could come to think, presentism ought to be true (provided, one might prudentially add, the Big Crunch hypothesis is not true). And, given the theoretical stalemate, they might thus come to embrace presentism from a practical point of view and take it to be actually true. In an analogous fashion, Kant suggests in his second Critique that certain propositions that cannot be proven theoretically can be accepted from a practical standpoint.

Moreover, for those who believe in an omnipotent and benevolent Deity or attribute ontological efficacy to values (see, e.g., Leslie 2013 and references therein), the moral superiority of presentism proclaimed by $(\mathrm{C})$ should even be more compelling, perhaps up to the point of leading them to revise their ontology, if it is a non-presentist ontology. From their perspective, it seems to me, the temptation to infer that presentism is true from the proposition that it ought to be true should be particularly high and thus anti-presentist ontological beliefs or sympathies (see. e.g., Leslie 2013, pp. 138-139), if any, should be seriously questioned. Moreover, as they see matters, the ideal of a future 
pure world with absolute well-being and no sorrow ${ }^{14}$ could perhaps be seen as more realistic than the Big Crunch hypothesis; the latter could then be put to rest, unless of course the disappearance of a physical universe is not deemed so important after all, given the faith in a purely spiritual paradise.

\section{Conclusion}

The argument for the moral superiority of presentism advanced here faces a number of difficult objections. Yet, it seems to me that it withstands scrutiny. At the very least, it offers some interesting food for thought. If its conclusion stands, the argument could or should incline toward presentism at least those who think that the presentism vs. non-presentism dispute cannot be resolved on purely theoretical grounds. Moreover, given a fundamental commitment to the ontological efficacy of values, whether theistic or not in nature, it should even more compellingly lead to an endorsement of presentism. ${ }^{15}$

\section{References}

Bigelow, J. 1996. "Presentism and Properties," Philosophical Perspectives, 10, pp. 35-52.

Bourne, C. 2006. A Future for Presentism, Oxford: Oxford University Press.

Chen, C. K. 2011. "Subjectivity and the Metaphysics of Time," in The Possibility of Philosophical Understanding: the Philosophy of Barry Stroud, eds. J. Bridges, N. Kolodny and W. Wong. Oxford: Oxford University Press.

Crisp, T. 2007. "Presentism and the Grounding Objection," Noûs, 41, pp. 90-109.

Hoerl, C. 2015. “Tense and the Psychology of Belief,” Topoi, 34, pp. 217-231.

Keller, S. 2004. "Presentism and Truthmaking," in Zimmerman 2004, pp. 83-104.

Leslie, J. 2013. "A Proof of God's Reality" in The Puzzle of Existence. Why There is Something Rather than Nothing?, ed. T. Goldschmidt, pp. 128-143, London: Routledge.

MacBeath, M. 1983. “Mellor's Emeritus Headache,” Ratio, 25, pp. 81-88.

MacLaurin, J. and Dyke, H. 2002. “'Thank Goodness That's Over.' The Evolutionary Story,” Ratio n.s. 15, pp. 276-292.

\footnotetext{
${ }^{14}$ At least no sorrow of the innocent, or, following von Balthasar's idea of an empty hell, no sorrow in general.

${ }^{15}$ I wish to thank for their valuable comments Ernesto Graziani, Tomis Kapitan, Greg Landini, Nathan Oaklander, Michele Paolini Paoletti and the above mentioned anonymous referee.
} 
Markosian, N. 2010. "Time," in The Stanford Encyclopedia of Philosophy, ed. E. N. Zalta, Winter 2010 Edition) URL $=\underline{\text { http://plato.stanford.edu/archives/win2010/entries/time/, }}$

Mellor, D. H. 1998. Real Time II. London: Routledge.

Merricks, T. 2007. Truth and Ontology, Oxford: Oxford University Press.

Oaklander, L. N. 2003. "Two Versions of the New Theory of B-Language," in Time, Tense and Reference, ed. A. Jokic and Q. Smith, Cambridge, Mass.: MIT Press, pp. 271-303.

Oaklander, L. N. 2015, “Temporal Phenomena, Ontology and the R-theory,” Metaphysica, 16, 253-269.

Orilia, F. 2012. Filosofia del Tempo. Il Dibattito contemporaneo, Roma: Carocci.

Orilia, F. 2014. "Two metaphysical perspectives on the duration of the present," in L. N. Oaklander, ed., Debates in the Metaphysics of Time, London: Bloomsbury, pp. 51-70.

Orilia, F. 2016. “Moderate Presentism,” Philosophical Studies, 173, pp. 589-607.

Orilia, F. and Oaklander L. N. 2015. "Do We Really Need a New B-Theory of Time?," Topoi, 34, pp. $157-170$.

Prior, A. N. 1959. “Thank Goodness That's Over,” Philosophy, 34, pp. 12-17.

Prior, A. N. 1996. "Some Free Thinking About Time," in J. Copeland, ed., Logic and Reality. Essays on the Legacy of Arthur Prior, Oxford: Clarendon Press, pp. 271-303.

Rawls, J. B. 1971. A Theory of Justice, Cambridge, MA: Harvard University Press.

Schlesinger, G. 1980. Aspects of Time, Indianapolis: Hackett.

Smart, J. J. C. 2008. “The Tenseless Theory of Time,” in Sider et al. 2008, pp. 226-238.

Turri, J. 2013. “That's Outrageous,” Theoria, pp. 79, pp. 167-171.

Sider, T., Hawthorne, J. and Zimmerman, D. W. (eds.) 2008. Contemporary Debates in Metaphysics, Oxford: Blackwell.

Williamson, T. 2002. Necessary Existents, in A. O’Hear (ed.), Logic, Thought and Language, Cambridge University Press, Cambridge, pp. 233-251.

Zimmerman, D. 2008. “The Privileged Present: Defending an "A-theory" of Time," in Sider et al. 2008, pp. 211-225. 